\title{
Dissecting Morphological and Molecular Heterogeneity in Adrenocortical Carcinoma
}

\author{
Eleonora DUREGON, Marco VOLANTE, Ida RAPA, Simona VATRANO, Mauro PAPOTTI
}

Department of Oncology, University of Turin at San Luigi Hospital, ORBASSANO, TURIN, ITALY

\begin{abstract}
Adrenocortical carcinoma is generally considered a single entity by pathologists and clinicians. Nevertheless, the knowledge cumulated along the last decade on the pathological characterization, the clinical outcome and the molecular pathogenesis of adrenocortical carcinoma demonstrate that one of the most relevant emerging issues is related to its heterogeneity. Three major morphological variants have been described (oncocytic, myxoid and sarcomatoid) but are not included in the current WHO classification, yet. Moreover, even "conventional" adrenocortical carcinomas have a high degree of morphological heterogeneity as well as different mitotic/proliferative capacity, either among different cases or within individual lesions. Furthermore, immunohistochemical and molecular studies, based on a wide set of different methodologies, identified novel biomarkers in adrenocortical carcinoma of diagnostic and prognostic relevance, which claimed again the concept that this tumor type represents an heterogeneous group of neoplasms which cannot be considered a unique entity. The integration between morphology, immunophenotype and molecular data is expected in the next years to build a novel concept of adrenocortical carcinoma classification into specific subgroups, as it is currently approached for other types of neoplasms such as breast or lung cancer, which are not merely descriptive, but also characterized by a specific biological and clinical behavior.
\end{abstract}

Key Words: Adrenocortical carcinoma, Heterogeneity, Variants, Immunohistochemistry, Molecular pathology

\section{INTRODUCTION}

When facing an adrenal neoplasm, pathologists are asked to solve three major issues: first, to differentiate adrenocortical primaries from metastases and other primary tumors of the adrenal gland such as medullary tumors and sarcomas; second, to distinguish adrenocortical adenoma from carcinoma; third, to predict the clinical behavior of carcinoma. In the last decades, a notable progress has been obtained to better refine the diagnostic criteria of adrenocortical neoplasms, with special reference to the first two above points, thus limiting the number of problematic cases. The available diagnostic systems, such as the Weiss Score (1), have been more widely adopted worldwide and simplified (2), or were implemented by alternative approaches (3). However, adrenocortical carcinoma (ACC) is generally considered a single entity by pathologists and clinicians. No specific variants are described in the current WHO classification (4), nor a grading system is currently validated. Nevertheless, the experience made at our Institution on large series $(3,5)$, as well as the knowledge cumulated along the last decade on the clinical outcome and molecular pathogenesis of ACC, demonstrate that one of the most relevant emerging issues is related to ACC heterogeneity. In fact, at least three morphological variants exist and even "conventional" ACCs have a high degree of

(Turk Patoloji Derg 2015, 31(Suppl):98-104)

Received : 22.06.2015 Accepted : 22.06.2015 morphological heterogeneity, either among different cases or within individual lesions. Concurrently, the clinical outcome of ACC patients is variable and poorly predictable, including cases with an indolent clinical course and tumors having an aggressive and fatal outcome. Finally, ACC have a heterogeneous molecular background, which is apparently unrelated to the morphological features.

Based on the aforementioned, in this review we will focus on the morphological, immunophenotypical and molecular features, which support the concept that ACC is an heterogeneous disease and possibly have an impact on its pathological classification as well as on its clinical management and prognostic stratification.

\section{ADRENOCORTICAL CARCINOMA VARIANTS}

\section{Oncocytic Adrenocortical Carcinoma}

Oncocytic adrenocortical neoplasms are the most represented among the morphological variants of ACC, accounting for approximately $18 \%$ of ACC at our Institution (6). They are characterized by the presence of large and pleomorphic cells with a granular and deeply eosinophilic cytoplasm, which may be predominant or represent a minority of the tumor cell population. The architectural features may vary from solid growth to trabecular to

Correspondence: Marco VOLANTE

Department of Oncology, University of Turin at San Luigi Hospital,

Regione Gonzole 10, 10043 ORBASSANO, TORINO, ITALY

E-mail: marco.volante@unito.it Phone: +390116705464 
glandular (Figure 1A,B). Such features are overlapping those of oncocytic neoplasms of other sites, such as the thyroid and salivary glands, and similarly to these sites the mitochondrial DNA "common deletion" (4977 base pairs) has been found in approximately $40 \%$ of cases, more frequently in borderline and benign tumors (6). In the presence of predominant oncocytic features, the Weiss Score is inadequate to define malignancy, as three out nine parameters (eosinophilic cytoplasm, high nuclear grade and diffuse architecture) are intrinsically present. Therefore to avoid an over-diagnosis of malignancy in this special subset, and alternative approach, the Lin-Weiss-Bisceglia system was specifically proposed and defines oncocytic ACC in the presence of at least one of three "major criteria" (mitotic rate $>5 \times 50$ high power fields, atypical mitoses, and/or venous invasion), and oncocytic adrenal cortical neoplasm of borderline malignancy in the presence of at least one of four "minor criteria" (necrosis, capsular and sinusoidal invasion, size $>10 \mathrm{~cm}$ or weight $>200 \mathrm{~g}$ ) (7). This classification correctly predicts the malignant potential of these tumors, which indeed have a more favorable prognosis as compared to conventional ACC (8). Diagnostic algorithms alternative to the Weiss Score, such as the reticulin algorithm, also proved effective in correctly taking benign apart from malignant cases (6).

\section{Myxoid Adrenocortical Carcinoma}

Extracellular deposits of myxoid material characterize the myxoid ACC variant (Figure 1C,D), which accounts for approximately $10 \%$ of cases $(9,10)$, although focal myxoid areas $(<20 \%$ of the tumor) can be rather frequently observed also in otherwise conventional ACC. Moreover,

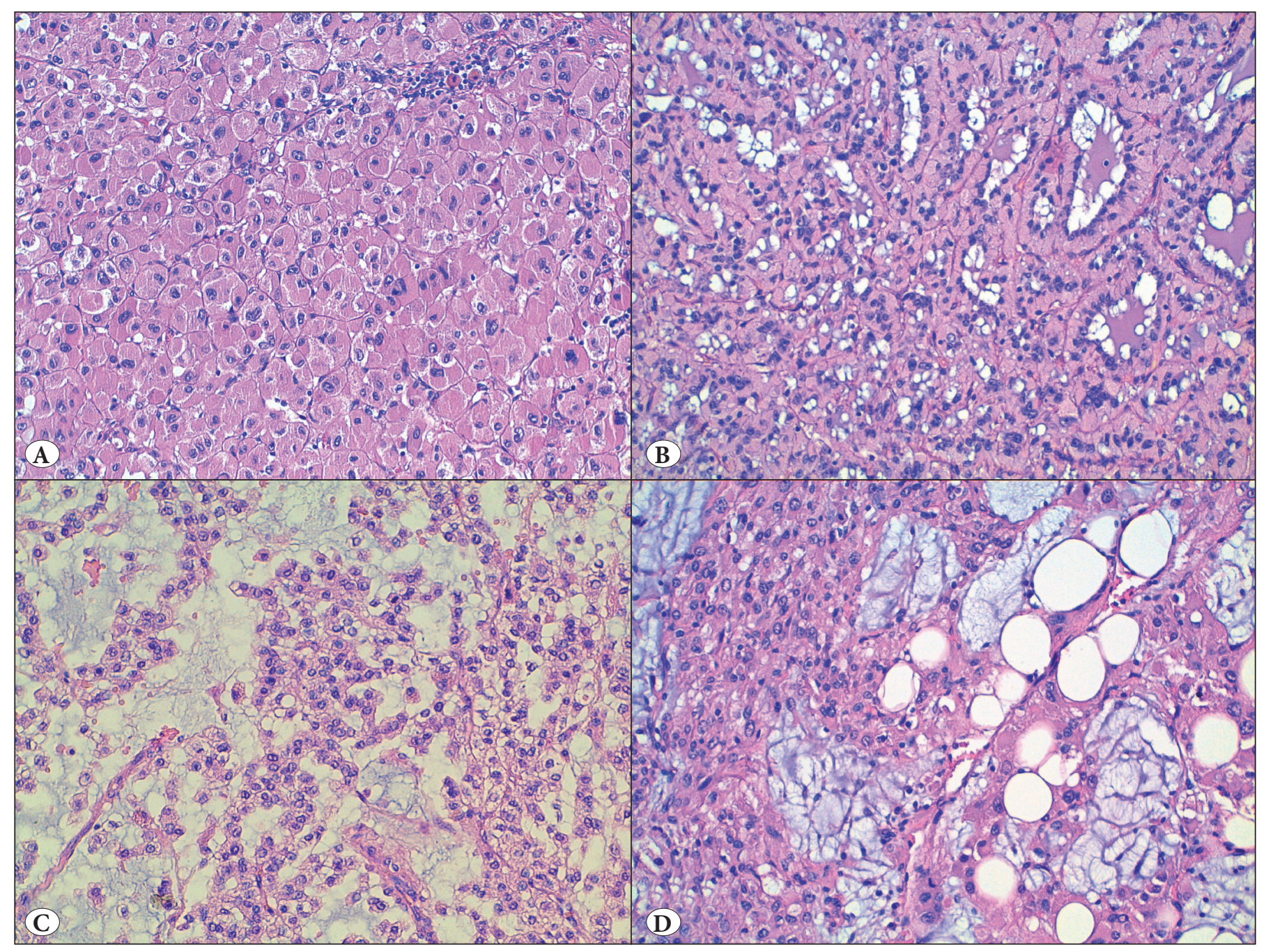

Figure 1: Adrenocortical carcinoma variants. A) The oncocytic variant, with predominant solid or B) pseudo-glandular growth patterns, and $\mathbf{C}$ ) the myxoid variant with predominant deposits of myxoid material and D) focal lipomatous changes. (H\&E staining, original magnification 200x). 
this variant, independently from the abundance of myxoid material, is characterized by small to medium sized monotonous cells with mild to moderate nuclear atypia, scant lightly eosinophilic cytoplasm, and a trabecular, pseudoglandular or cribriform pattern of growth. As a consequence, in myxoid tumors, the Weiss parameters of diffuse growth and nuclear atypia are usually absent and the identification of invasive areas in the presence of abundant myxoid background might be hardly assessable, leading to the risk of underestimating malignancy. The clinical behavior of myxoid ACC is comparable to or sometimes more aggressive than conventional ACC, and in adrenal tumors with predominant myxoid stroma it is advisable to have a high index of suspicion for malignancy even in the presence of an apparently benign tumor at first glance.

\section{Sarcomatoid Adrenocortical Carcinoma}

ACC with a sarcomatoid morphology are extremely rare and to the best of our knowledge only 16 cases have been reported, so far. Sarcomatoid ACC are highly aggressive, and a cut-off of $10 \%$ of sarcomatous component to diagnose this unusual variant has been proposed, independently from the Weiss Score (11). Based on the presence of spindle cell areas or a specialized mesenchymal component, (osteosarcomatous, chondrosarcomatous, rhabdomyosarcomatous or primitive neuroectodermal) they can be classified into sarcomatoid carcinomas or carcinosarcomas, respectively, although the clinical meaning of such a distinction is not assessed, yet.

\section{MORPHOLOGICAL HETEROGENEITY IN CONVENTIONAL ADRENOCORTICAL CARCINOMA}

Since the introduction of Weiss Score (12), the focus of pathologists has been captured to refine or replace this system in order to optimize the distinction between benign and malignant tumors. No specific attention has been paid to the different morphological aspects of ACC (with the notable exception of the three variants), conveying the idea that ACC are morphologically all the same. Conversely, within the so called "conventional" ACC, different morphological features can be identified and characterized by the predominance of either highly pleomorphic large cells, monotonous small to medium sized cells ("carcinoidlike"), or rhabdoid cells growing in alveolar structures (Figure 2A-D). Five adrenocortical tumors of this latter group have been reported so far, one adenoma (13) and four carcinomas $(14,15)$, and are characterized by a diffuse or alveolar growth of neoplastic cells with prominent eosinophilic cytoplasmic inclusions, eccentric vesicular nuclei and prominent nucleoli.
Moreover, ACCs very frequently display a mixture of different patterns, either in terms of architecture or of cytological features. Nevertheless, no data are available in the literature trying to correlate peculiar growth patterns or the presence of marked intratumoral heterogeneity with specific biological or clinical characteristics. In addition, in rare cases of ACC intratumoral heterogeneity is represented by a tumor component morphologically resembling adrenocortical adenoma and characterized by the preservation of the reticulin framework and mitotic/ proliferation indexes much less pronounced than the overtly malignant component (5). Although only anecdotal cases have been reported in the literature (16), such cases are supportive of the concept of an adenoma-to-carcinoma pathogenetic sequence at least for a subset of ACC, which has been postulated also based on recent molecular findings $(17,18)$. Myelo-lipomatous changes are much less frequent than in adrenocortical adenoma, but few cases have been reported $(19,20)$. Marked pigmentation may occur in a subset of adrenocortical adenomas, thus called black adenomas, but exceptional cases of malignant pigmented adrenocortical neoplasm with late recurrence and metastasis associated with Cushing's syndrome have been also described (21).

\section{IMMUNOPHENOTYPICAL HETEROGENEITY IN ADRENOCORTICAL CARCINOMA}

In adrenal tumor pathology, immunohistochemistry is frequently employed to differentiate adrenocortical lesions from medullary, non-endocrine and metastatic tumors. Melan-A (MART-1), alpha-inhibin, calretinin, synaptophysin, and the more recent Steroidogenic Factor 1 (SF-1) are the markers most commonly used to support the adrenocortical origin of a tumor, and novel markers such as D2-40 are under validation. SF-1 is apparently the marker having the best sensitivity (98\%) and specificity $(100 \%)(22$, 23), while all other markers have a heterogeneous pattern of reactivity and are immunoreactive in a fraction of cases, only. However, such an heterogeneous expression has been poorly associated to specific tumor characteristics. Alphainhibin was reported to be expressed mostly in androgen secreting adrenal cortical neoplasms (24) and to a lower extent in cortisol and aldosterone producing neoplasms. The immunohistochemical reactivity of myxoid and oncocytic ACC variants is similar to those of the conventional type (7, $9,10)$. However, in the myxoid variant, neurofilaments are more frequently and extensively expressed, as compared to conventional ACC (9). Sarcomatous areas of sarcomatoid ACC usually lose the expression of adrenocortical specific markers such as SF-1 and Melan-A (Duregon unpublished 


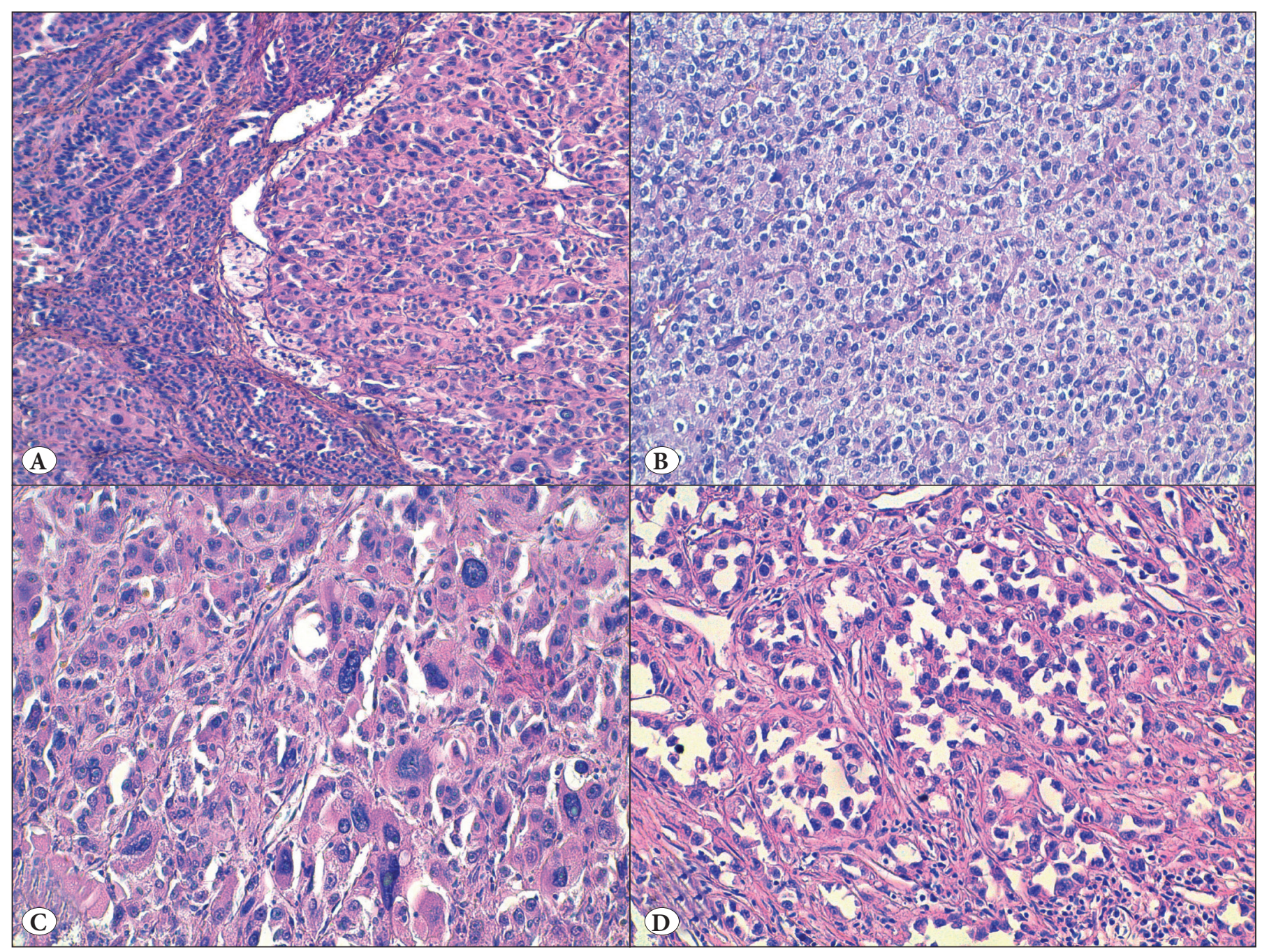

Figure 2: Heterogeneity of "conventional" adrenocortical carcinoma. A) Intratumoral architectural and cytological heterogeneity in a case of adrenocortical carcinoma. B) Predominant cytological/architectural patterns include the solid ("carcinoid-like") with uniform cells, C) the solid/trabecular with highly pleomorphic cells, and D) the alveolar with rhabdoid cells. (H\&E staining, original magnifications: a, b and d 200x, c 400x).

results). Moreover, the heterogeneous expression of SF-1 has also been validated in multiple cohorts as a marker of poor prognosis when expressed at high levels $(22,23)$. Accordingly, oncocytic ACC were found to have a lower expression of SF-1 in terms of intensity, as compared to conventional ones (23).

\section{THE CONCEPT OF LOW AND HIGH GRADE ADRENOCORTICAL CARCINOMA}

Apart from the distinction between benign and malignant tumors, an emerging issue in ACC pathology is the definition of prognostic parameters, which might help the clinicians to define the most correct therapeutic strategies. In fact, the biological and clinical behavior of ACC is extremely variable, from indolent to very aggressive neoplasms. Weiss
Score per se was never demonstrated to bear a prognostic role by segregating tumors with low (i.e. Weiss 3 ) from those with high scores. Conversely, mitotic count represents a major parameter associated with patients' prognosis, and reflects the extreme heterogeneity in the proliferative capacity of ACC. A two-tier grading system exclusively based on mitotic count was developed with a cut off of 20 mitoses per 50 high power fields to separate low from high grade adrenal cortical carcinomas (25). In our experience, a mitotic index above 9 mitoses per 50 high power fields was also an independent adverse prognostic parameter (3). Recently, phospho-histone H3 immunostaining was demonstrated to be a faster and reliable method to highlight mitotic figures, particularly useful in cases with low mitotic activity, thus producing a higher inter-observer 
agreement (26). Moreover, several groups proved that Ki-67 is superior to mitotic count to prognosticate ACC, although the optimal cut offs are still to be identified among those sp far proposed - by Duregon et al. (26) $(<20 \%, 20-50 \%$ and $>50 \%)$ and by Beuschlein et al. (27) $(<10 \%, 10-20 \%)$ In addition, as for several other cancer types, the mitotic/ proliferative activity within individual lesions is frequently heterogeneous (Figure 3) and the evaluation of hot-spot areas is preferable, as also recently suggested (28).

\section{MOLECULAR HETEROGENEITY IN ADRENOCORTICAL CARCINOMA}

Genomic, transcriptomic, methylome profiles and miRNA have been investigated in the last decade to depict the molecular background of ACC, demonstrating also the existence of specific molecular subgroups strongly associated with poor and good prognosis. Among the most studied genes, IGF2 has been found to be heterogeneously expressed both in indolent and aggressive tumors (29, 30 ), suggesting that the alteration of the IGF2 locus with subsequent increase of IGF2 expression is an early event in a subset of ACC lacking specific biological and clinical characteristics. Conversely, somatic alterations of TP53 and CTNNB1 were found to be mutually exclusive and were observed only in poor-outcome ACCs (31), suggesting a late involvement of these mutations in adrenocortical carcinoma development. Genome-wide assessment of copy number changes (32), DNA methylation studies (33) and
miRNA profiling (34) divided adrenocortical carcinomas into specific groups with distinct survival. Recently, these data have been implemented by comprehensive DNA analysis by means of next generation sequencing (NGS) (35-38). TP53 and CTNNB1 were confirmed as the most recurrent mutated genes across ACC genome. Moreover, among a variety of observed genetic alterations, recurrent homozygous deletions of ZNRF3 and KREMEN1 $(35,38)$ and TERT amplifications/promoter mutations (38-40) were more commonly found, all mutually exclusive. However, the correlation of molecular data with specific pathological (i.e. histological variant, proliferative capacity, peculiar morphological pictures) or clinical (i.e. stage, outcome) characteristics is still poor. In the paper by Ross et al. (36), an amplification of the PDGFR-beta gene, which has never been described before, was found in an oncocytic ACC. In another study by our group, heterogeneous expression of selected miRNAs was detected among ACC variants (41). Moreover, a near-homozygous genome was demonstrated in a subset of $55 \%$ of oncocytic adrenal cortical tumors (42), an event which occurs also in oncocytic thyroid and parathyroid neoplasms.

\section{CONCLUSIONS}

For over 25 years, morphology has been the mainstay to differentiate adrenocortical carcinoma from adenoma. However, in more recent years, morphological heterogeneity was recognized as the hallmark to identify distinctive

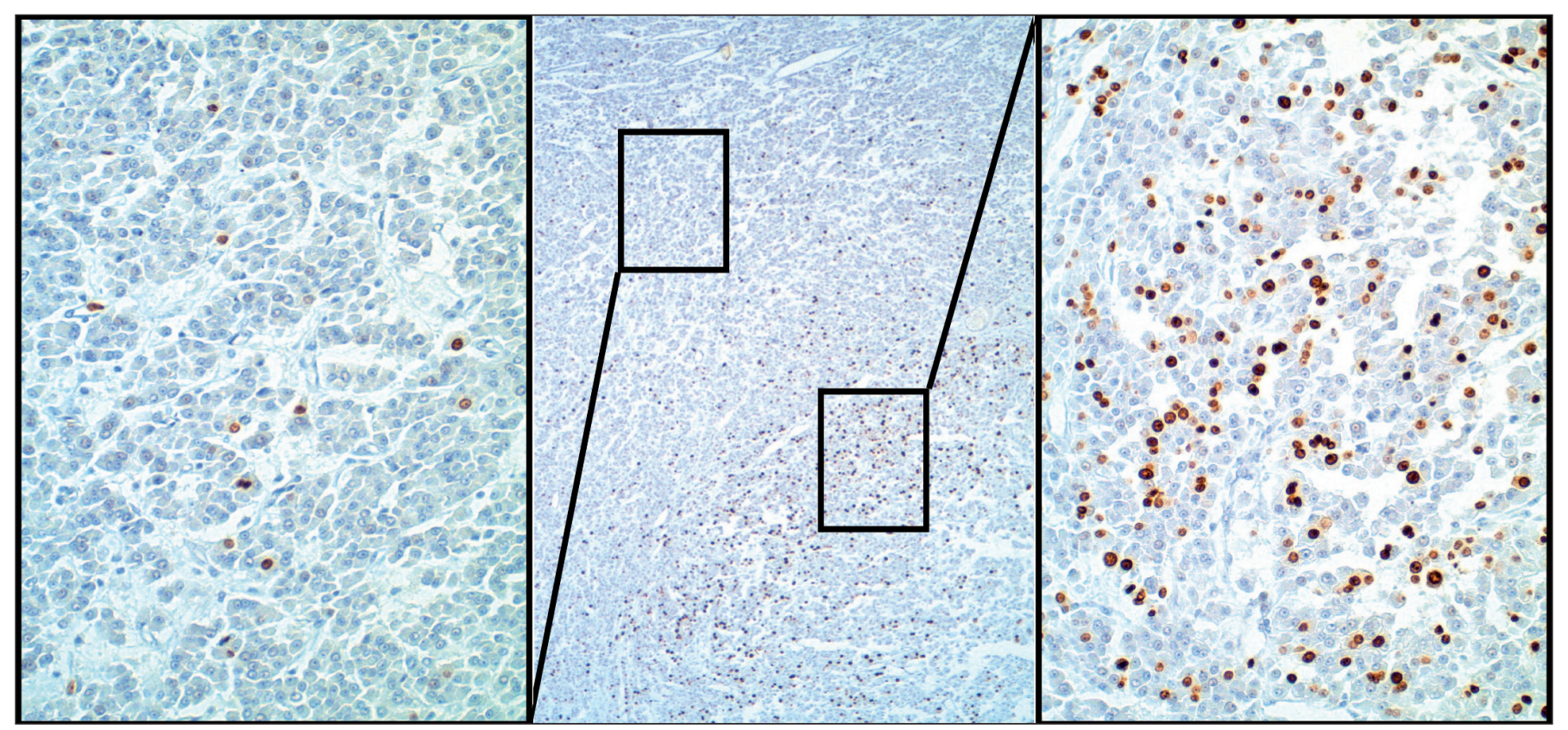

Figure 3: Heterogeneity of proliferative activity in adrenocortical carcinoma. Different tumor areas of the same tumor showed extremely variable Ki-67 proliferation indexes. (Immunoperoxidase staining, original magnifications: main panel 100x, enlarged panels 400x). 
ACC variants, which are not merely morphology-based, but also characterized by specific biological and clinical behavior, at least as far the oncocytic variant is concerned. In parallel, immunohistochemical and molecular studies based on a wide set of different methodologies identified novel biomarkers in ACC having a diagnostic and prognostic role. This further supports the concept that ACC belongs to a heterogeneous group of neoplasms and cannot be considered a unique entity. The integration among morphology, proliferative potential, tumor grade, immunophenotype and molecular data is expected in the next years to design novel ACC classification schemes that recognize specific clinically-relevant subgroups, as it is currently happening in other types of neoplasms, such as breast or lung cancer.

\section{SOURCE of FUNDING}

MP is currently receiving a grant from AIRC, Milan (no. IG/14820/2013).

\section{CONFLICTS OF INTEREST}

All Authors have no potential conflicts of interest to declare.

\section{REFERENCES}

1. Weiss LM, Medeiros LJ Vickery AL Jr. Pathologic features of prognostic significance in adrenocortical carcinoma. Am J Surg Pathol. 1989;13:202-6.

2. Aubert S, Wacrenier A, Leroy X, Devos P, Carnaille B, Proye C, Wemeau JL, Lecomte-Houcke M, Leteurtre E. Weiss system revisited: A clinicopathologic and immunohistochemical study of 49 adrenocortical tumors. Am J Surg Pathol. 2002;26:1612-9.

3. Volante M, Bollito E, Sperone P, Tavaglione V, Daffara F, Porpiglia F, Terzolo M, Berruti A, Papotti M. Clinicopathological study of a series of 92 adrenocortical carcinomas: From a proposal of simplified diagnostic algorithm to prognostic stratification. Histopathology. 2009;55:535-43.

4. DeLellis RA, Lloyd R, Heitz PU, Eng C. WHO Classification of Tumours of the Endocrine Organs. 3RD ed. Lyon: 2004

5. Duregon E, Fassina A, Volante M, Nesi G, Santi R, Gatti G, Cappellesso R, Dalino Ciaramella P, Ventura L, Gambacorta M, Dei Tos AP, Loli P, Mannelli M, Mantero F, Berruti A, Terzolo M, Papotti M. The reticulin algorithm for adrenocortical tumor diagnosis: A multicentric validation study on 245 unpublished cases. Am J Surg Pathol. 2013;37:1433-40.

6. Duregon E, Volante M, Cappia S, Cuccurullo A, Bisceglia M, Wong DD, Spagnolo DV, Szpak-Ulczok S, Bollito E, Daffara F, Berruti A, Terzolo M, Papotti M. Oncocytic adrenocortical tumors: Diagnostic algorithm and mitochondrial DNA profile in 27 cases. Am J Surg Pathol. 2011;35:1882-93.

7. Bisceglia M, Ludovico O, Di Mattia A, Ben-Dor D, Sandbank J, Pasquinelli G, Lau SK, Weiss LM. Adrenocortical oncocytic tumors: Report of 10 cases and review of the literature. Int J Surg Pathol. 2004;12:231-43.
8. Wong DD, Spagnolo DV, Bisceglia M, Havlat M, McCallum D, Platten MA. Oncocytic adrenocortical neoplasms-a clinicopathologic study of 13 new cases emphasizing the importance of their recognition. Hum Pathol. 2011;42:489-99.

9. Papotti M, Volante M, Duregon E, Delsedime L, Terzolo M, Berruti A, Rosai J. Adrenocortical tumors with myxoid features: A distinct morphologic and phenotypical variant exhibiting malignant behavior. Am J Surg Pathol. 2010;34:973-83.

10. Weissferdt A, Phan A, Suster S, Moran CA. Myxoid adrenocortical carcinoma: A clinicopathologic and immunohistochemical study of 7 cases, including 1 case with lipomatous metaplasia. Am J Clin Pathol. 2013;139:780-6.

11. Sturm N, Moulai N, Laverriere MH, Chabre O, Descotes JL, Brambilla E. Primary adrenocortical sarcomatoid carcinoma: Case report and review of literature. Virchows Arch. 2008; 452:215-9.

12. Weiss LM. Comparative histologic study of 43 metastasizing and nonmetastasizing adrenocortical tumors. Am J Surg Pathol. 1984; 8:163-9.

13. Dundr P, Povysil C, Zelinka T, Tvrdik D, Ciprova V, Novak K. Adrenocortical adenoma with rhabdoid features. Pathol Res Pract. 2006;2:177-81.

14. Lou E, Goodwin J, Howell DN, Hicks J, Caram LB. A G-CSFsecreting adrenal carcinoma with rhabdoid-like differentiation causing leukocytosis. Nat Rev Urol. 2009;6:392-7.

15. Weissferdt A, Phan A, Suster S, Moran CA. Primary rhabdoid adrenocortical carcinoma: A clinicopathological and immunohistochemical study of three cases. Histopathology 2013; 62:771-7.

16. Ranganathan S, Lynshue K, Hunt JL, Kane T, Jaffe R. Unusual adrenal cortical tumor of unknown biologic potential: A nodule in a nodule in a nodule. Pediatr Dev Pathol. 2005;8:483-8.

17. Ronchi CL, Sbiera S, Leich E, Henzel K, Rosenwald A, Allolio $\mathrm{B}$, Fassnacht M. Single nucleotide polymorphism array profiling of adrenocortical tumors - evidence for an adenoma carcinoma sequence? PLoS One. 2013;8:e73959.

18. Heaton JH, Wood MA, Kim AC, Lima LO, Barlaskar FM, Almeida MQ, Fragoso MC, Kuick R, Lerario AM, Simon DP, Soares IC, Starnes E, Thomas DG, Latronico AC, Giordano TJ, Hammer GD. Progression to adrenocortical tumorigenesis in mice and humans through insulin-like growth factor 2 and beta-catenin. Am J Pathol. 2012;181:1017-33.

19. Sun X, Ayala A, Castro CY. Adrenocortical carcinoma with concomitant myelolipoma in a patient with hyperaldosteronism. Arch Pathol Lab Med. 2005;129:e144-7.

20. Wang J, Fisher C, Thway K. "Dominant” myelolipoma encasing adrenal cortical carcinoma: An unusual variation of myelolipoma occurring as a synchronous and predominant neoplasm. Int J Surg Pathol. 2014;22:731-5.

21. Geller JL, Azer PC, Weiss LM, Mertens RB. Pigmented adrenocortical carcinoma: Case report and review. Endocr Pathol. 2006;17:297-304. 
22. Sbiera S, Schmull S, Assie G, Voelker HU, Kraus L, Beyer M, Ragazzon B, Beuschlein F, Willenberg HS, Hahner S, Saeger W, Bertherat J, Allolio B, Fassnacht M. High diagnostic and prognostic value of steroidogenic factor-1 expression in adrenal tumors. J Clin Endocrinol Metab. 2010;95:E161-71.

23. Duregon E, Volante M, Giorcelli J, Terzolo M, Lalli E, Papotti M. Diagnostic and prognostic role of steroidogenic factor 1 in adrenocortical carcinoma: A validation study focusing on clinical and pathologic correlates. Hum Pathol. 2013;44:822-8.

24. Arola J, Salmenkivi K, Liu J, Kahri AI, Heikkila P. p53 and Ki67 in adrenocortical tumors. Endocr Res. 2000;26:861-5.

25. Miller BS, Gauger PG, Hammer GD, Giordano TJ, Doherty GM. Proposal for modification of the ENSAT staging system for adrenocortical carcinoma using tumor grade. Langenbecks Arch Surg 2010;395:955-61.

26. Duregon E, Molinaro L, Volante M, Ventura L, Righi L, Bolla S, Terzolo M, Sapino A, Papotti MG. Comparative diagnostic and prognostic performances of the hematoxylin-eosin and phosphohistone H3 mitotic count and Ki-67 index in adrenocortical carcinoma. Mod Pathol 2014;27:1246-54.

27. Beuschlein F, Weigel J, Saeger W, Kroiss M, Wild V, Daffara F, Libe R, Ardito A, Al Ghuzlan A, Quinkler M, Osswald A, Ronchi CL, de Krijger R, Feelders RA, Waldmann J, Willenberg HS, Deutschbein T, Stell A, Reincke M, Papotti M, Baudin E, Tissier F, Haak HR, Loli P, Terzolo M, Allolio B, Muller HH, Fassnacht M. Major prognostic role of Ki67 in localized adrenocortical carcinoma after complete resection. J Clin Endocrinol Metab. 2015;100:841-9.

28. Lu H, Papathomas TG, van Zessen D, Palli I, de Krijger RR, van der Spek PJ, Dinjens WN, Stubbs AP. Automated Selection of Hotspots (ASH): Enhanced automated segmentation and adaptive step finding for Ki67 hotspot detection in adrenal cortical cancer. Diagn Pathol. 2014;9:216.

29. de Reynies A, Assie G, Rickman DS, Tissier F, Groussin L, ReneCorail F, Dousset B, Bertagna X, Clauser E, Bertherat J. Gene expression profiling reveals a new classification of adrenocortical tumors and identifies molecular predictors of malignancy and survival. J Clin Oncol. 2009;27:1108-15.

30. Giordano TJ, Kuick R, Else T, Gauger PG, Vinco M, Bauersfeld J, Sanders D, Thomas DG, Doherty G, Hammer G. Molecular classification and prognostication of adrenocortical tumors by transcriptome profiling. Clin Cancer Res. 2009;15:668-76.

31. Ragazzon B, Libe R, Gaujoux S, Assie G, Fratticci A, Launay P, Clauser E, Bertagna X, Tissier F, de Reynies A, Bertherat J. Transcriptome analysis reveals that p53 and \{beta\}-catenin alterations occur in a group of aggressive adrenocortical cancers. Cancer Res. 2010;70:8276-81.

32. Barreau O, de Reynies A, Wilmot-Roussel H, Guillaud-Bataille M, Auzan C, Rene-Corail F, Tissier F, Dousset B, Bertagna X, Bertherat J, Clauser E, Assie G. Clinical and pathophysiological implications of chromosomal alterations in adrenocortical tumors: An integrated genomic approach. J Clin Endocrinol Metab. 2012;97:E301-11.
33. Barreau O, Assie G, Wilmot-Roussel H, Ragazzon B, Baudry C, Perlemoine K, Rene-Corail F, Bertagna X, Dousset B, Hamzaoui N, Tissier F, de Reynies A, Bertherat J. Identification of a CpG island methylator phenotype in adrenocortical carcinomas. J Clin Endocrinol Metab. 2013;98:E174-84.

34. Igaz P, Igaz I, Nagy Z, Nyiro G, Szabo PM, Falus A, Patocs A, Racz K. MicroRNAs in adrenal tumors: Relevance for pathogenesis, diagnosis, and therapy. Cell Mol Life Sci. 2015;72:417-28.

35. Assie G, Letouze E, Fassnacht M, Jouinot A, Luscap W, Barreau O, Omeiri H, Rodriguez S, Perlemoine K, Rene-Corail F, Elarouci N, Sbiera S, Kroiss M, Allolio B, Waldmann J, Quinkler M, Mannelli M, Mantero F, Papathomas T, De Krijger R, Tabarin A, Kerlan V, Baudin E, Tissier F, Dousset B, Groussin L, Amar L, Clauser E, Bertagna X, Ragazzon B, Beuschlein F, Libe R, de Reynies A, Bertherat J. Integrated genomic characterization of adrenocortical carcinoma. Nat Genet. 2014;46:607-12.

36. Ross JS, Wang K, Rand JV, Gay L, Presta MJ, Sheehan CE, Ali SM, Elvin JA, Labrecque E, Hiemstra C, Buell J, Otto GA, Yelensky R, Lipson D, Morosini D, Chmielecki J, Miller VA, Stephens PJ. Nextgeneration sequencing of adrenocortical carcinoma reveals new routes to targeted therapies. J Clin Pathol. 2014;67:968-73.

37. De Martino MC, Al Ghuzlan A, Aubert S, Assie G, Scoazec JY, Leboulleux S, Do Cao C, Libe R, Nozieres C, Lombes M, Pattou F, Borson-Chazot F, Hescot S, Mazoyer C, Young J, Borget I, Colao A, Pivonello R, Soria JC, Bertherat J, Schlumberger M, Lacroix L, Baudin E. Molecular screening for a personalized treatment approach in advanced adrenocortical cancer. J Clin Endocrinol Metab. 2013;98:4080-8.

38. Juhlin CC, Goh G, Healy JM, Fonseca AL, Scholl UI, Stenman A, Kunstman JW, Brown TC, Overton JD, Mane SM, NelsonWilliams C, Backdahl M, Suttorp AC, Haase M, Choi M, Schlessinger J, Rimm DL, Hoog A, Prasad ML, Korah R, Larsson C, Lifton RP, Carling T. Whole-exome sequencing characterizes the landscape of somatic mutations and copy number alterations in adrenocortical carcinoma. J Clin Endocrinol Metab. 2015;100:E493-502.

39. Papathomas TG, Oudijk L, Zwarthoff EC, Post E, Duijkers FA, van Noesel MM, Hofland LJ, Pollard PJ, Maher ER, Restuccia DF, Feelders RA, Franssen GJ, Timmers HJ, Sleijfer S, de Herder WW, de Krijger RR, Dinjens WN, Korpershoek E. Telomerase reverse transcriptase promoter mutations in tumors originating from the adrenal gland and extra-adrenal paraganglia. Endocr Relat Cancer. 2014;21:653-61.

40. Liu T, Brown TC, Juhlin CC, Andreasson A, Wang N, Backdahl M, Healy JM, Prasad ML, Korah R, Carling T, Xu D, Larsson C. The activating TERT promoter mutation C228T is recurrent in subsets of adrenal tumors. Endocr Relat Cancer. 2014;21:427-34.

41. Duregon E, Rapa I, Votta A, Giorcelli J, Daffara F, Terzolo M, Scagliotti GV, Volante M, Papotti M. MicroRNA expression patterns in adrenocortical carcinoma variants and clinical pathologic correlations. Hum Pathol. 2014;45:1555-62.

42. Corver WE, van Wezel T, Molenaar K, Schrumpf M, van den Akker B, van Eijk R, Ruano Neto D, Oosting J, Morreau H. Near-haploidization significantly associates with oncocytic adrenocortical, thyroid, and parathyroid tumors but not with mitochondrial DNA mutations. Genes Chromosomes Cancer. 2014;53:833-44. 